\title{
RECENT APPROACHES IN GLUCOSE RESPONSIVE INSULIN DELIVERY SYSTEM
}

\author{
SAURABH SHARMA ${ }^{1}$, ASHUTOSH KASHYAP ${ }^{2}$, PRASANTA KUMAR BISWAL ${ }^{1}$, SURYA NARAYAN DAS ${ }^{1 *}$
}

${ }^{1}$ Department of Pharmaceutics, Gayatri College of Pharmacy, Sambalpur, Odisha, India. ${ }^{2}$ School of Pharmaceutical Sciences, Rajiv Gandhi Proudyogiki Vishwavidyalaya, Bhopal, Madhya Pradesh, India. Email: saurabhjsg@gmail.com

Received: 11 November 2021, Revised and Accepted: 01 January 2022

ABSTRACT

Diabetes mellitus is a chronic medical condition currently affecting 382 million people across the globe, caused due to increased blood glucose levels due to less insulin production or insulin resistance. Subcutaneous insulin administration for diabetes is the only most accepted therapy for maintaining blood glucose levels in diabetic patients. Many patients with advanced type II diabetes mellitus need to regularly monitor their blood glucose level to keep their blood glucose level in the target range. However long-term insulin therapy through an invasive route of administration causes problems with patient compliance and a sudden decrease in blood glucose levels. An artificial closed-loop insulin release system that mimics the glucose-responsive insulin secretion by $\beta$-cells of pancreas is one of the ways to overcome the problem faced with the conventional method of insulin administration. Many polymeric formulations showed an improved glucose-responsive release of insulin when incorporated with glucoseresponsive catalysts such as glucose oxidase, phenylboronic acid, and glucose binding proteins, the release rate can be controlled by optimizing the concentration of glucose-responsive catalysts. This article is been focused on different mechanisms of glucose-responsive release by incorporation with glucose-responsive catalysts.

Keywords: Glucose oxidase, Gluconic acid, Phenyl boronic acid, Concanavalin A, Hydrogen peroxide.

(C) 2022 The Authors. Published by Innovare Academic Sciences Pvt Ltd. This is an open access article under the CC BY license (http://creativecommons.org/ licenses/by/4.0/) DOI: http://dx.doi.org/10.22159/ajpcr.2022v15i2.43572. Journal homepage: https://innovareacademics.in/journals/index.php/ajpcr

\section{INTRODUCTION}

Diabetes mellitus is an autoimmune disorder in which glucose metabolism fails to maintain the normal glucose concentration in the body as a result of Wang et al. [1]. Insufficient production of insulin from pancreas due to destruction of $\beta$-cells of islets of Langerhans (type I diabetes) or [2] a combination of insulin resistance by cells and insufficient insulin secretion (Type II diabetes). Subcutaneous administration of insulin and regular monitoring of blood glucose is imperative for type I diabetes patients and some type II diabetes patients. However, conventional treatment of diabetes in which drug therapy and glucose sensing is not directly coupled, known as open-loop insulin delivery, does not tightly regulate glucose levels in patients $[53,54]$. To obliterate this problem one of the approaches is an artificial pancreas like a closed-loop insulin delivery system that can release insulin in response to changing blood glucose levels [52, 57]. This would also eradicate the risk of insulin-induced hypoglycemia; the potential of insulin treatment for glycemic control is not realized in numerous people with diabetes $[55,56]$.

To formulate such a closed-loop system usually consist of a glucosemonitoring moiety and an insulin-releasing module as depicted in Fig. $1[43,44]$. The current closed-loop system contains a glucose sensor and an external insulin infusion pump. However, the limitation in the application of such systems lies as the system lags in blood glucose feedback and biofouling $[50,51]$. An alternative to this is a chemically controlled glucose-responsive system that has been widely scrutinized during the last few decades. Typically, insulin embedded matrix with a glucose-responsive molecule can control insulin release through structural changes such as swelling, shrinkage, degradation, or dissociation in response to glucose concentration [48]. The commonly investigated glucose-responsive molecules include glucose oxidase (GOx), phenylboronic acid (PBA), and glucose binding proteins (GBP).

\section{GOX BASED MECHANISMS}

Glucose $+\mathrm{O}_{2}+\mathrm{H}_{2} \mathrm{O} \rightarrow$ GOx Gluconic Acid $+\mathrm{H}_{2} \mathrm{O}_{2}$
GOx is a flavin-containing glycoprotein that catalyzes glucose to produce hydrogen peroxide $\left(\mathrm{H}_{2} \mathrm{O}_{2}\right)$ and gluconic acid by consuming oxygen [49]. Erosion of polymer and release of endogenous substance (insulin) triggered by varying physiological environment by the effect of gluconic acid, hydrogen peroxide $\left(\mathrm{H}_{2} \mathrm{O}_{2}\right)$, and hypoxia condition [1-3]. Some of the research on GOX based insulin release system are summarized in Table 1.

\section{pH-responsive systems}

A common glucose-responsive moiety is $\mathrm{GOx}$, which catalyzes the oxidation of glucose to gluconic acid and hydrogen peroxide. The $\mathrm{pH}$ lowering effect that is derived from the generation of gluconic acid results in swelling of the GOx-entrapped pH-sensitive polymer, which subsequently releases insulin from the polymer matrix [4].

Conversion of glucose into gluconic acid causes a lowering in $\mathrm{pH}$ this will lead to cause conformational or structural change in the structure of the polymer to regulate the release of insulin [40, 42]. GOx enzyme is also sensitive to environmental changes and can be potentially denatured when it is entrapped in or covalently linked to a polymeric matrix shown in Fig. 2. Example of such strategies includes chitosan microgel [5], amphipathic 2-nitroimidazole-l-cysteine-alginate conjugates [6], and peptide hydrogel [2].

\section{Hypoxia-responsive system}

Glucoresponsive systems utilizing GOx as the responsive material for the release of insulin from the system generally consist of $\mathrm{pH}$ sensitive polymers, which are either protonated or degraded with the reduction in environmental $\mathrm{pH}$. But such $\mathrm{pH}$-dependent releases are often compromised by moderate or slow responsiveness, particularly in a buffered physiological environment. A novel glucose-responsive delivery system consisting of hypoxia sensitive polymer can be used for the release of insulin that shows much faster release as compared to the pH-sensitive release mechanism $[7,41]$.

This novel system of drug release comprising hypoxia sensitive polymer that consists of GOx cause conversion of glucose to gluconic acid which takes place with consumption of oxygen, this cause induction of hypoxia 




Fig. 1: Schematic representation of the dissociation of insulin glut complex in presence of free glucose and binding of insulin with insulin receptor and transport of glucose through glut

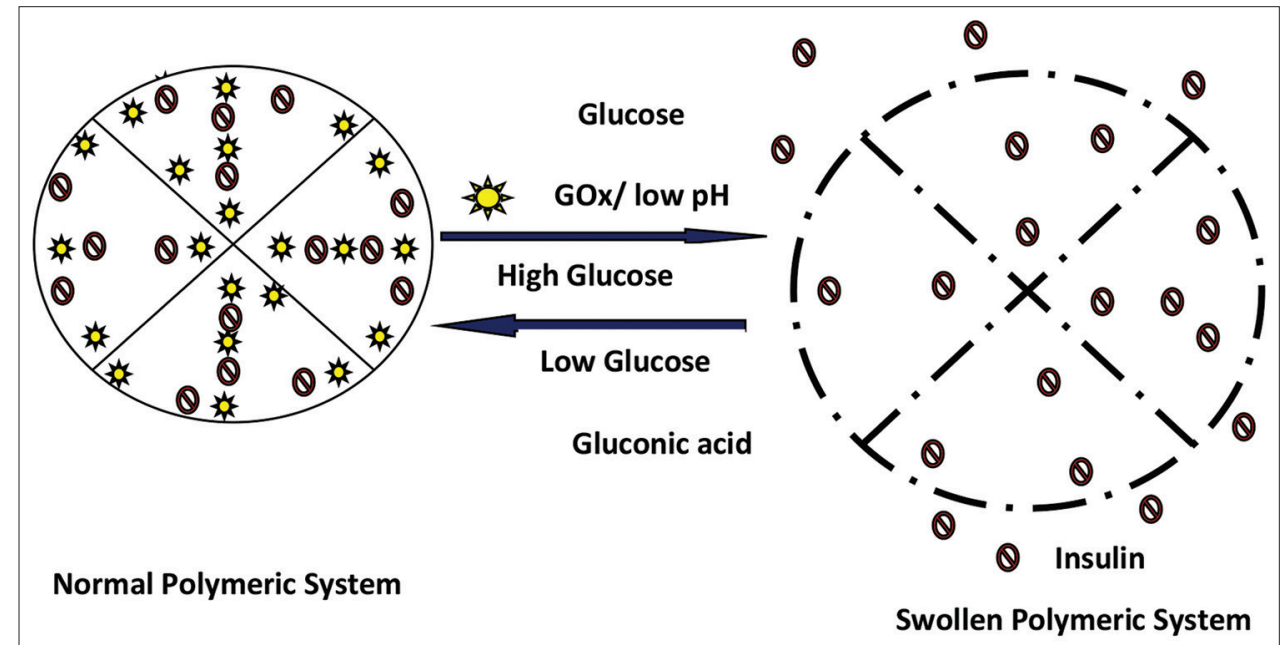

Fig. 2: Schematic representation of glucose triggered pH responsive insulin release system

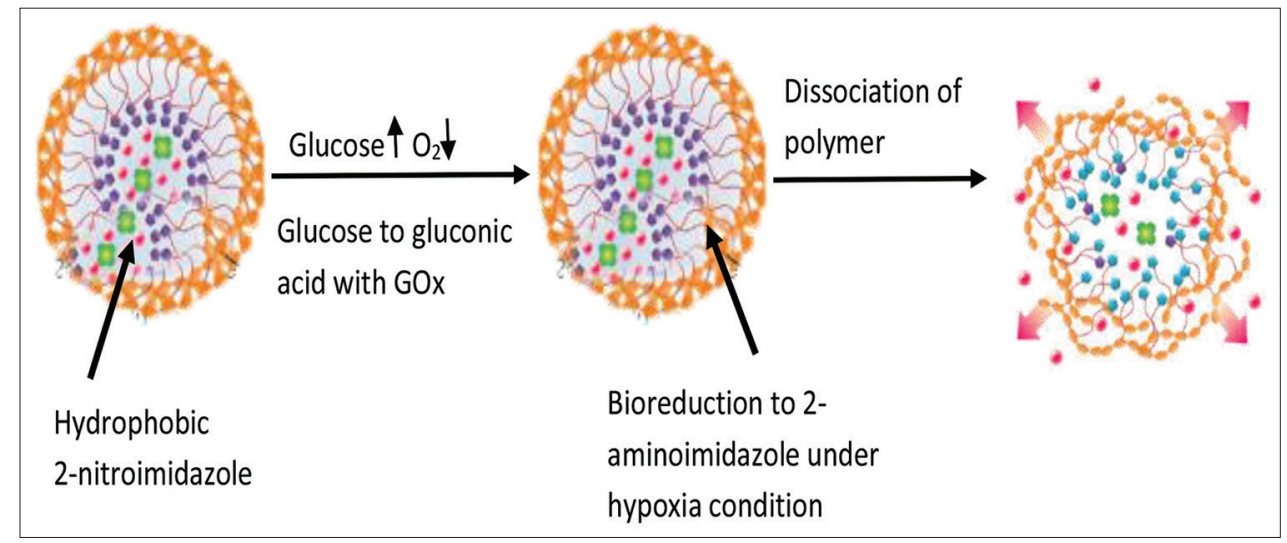

Fig. 3: Schematic representation of the dissociation of hypoxia mediated polymer and release of insulin

condition that causes degradation of polymer and release of the drug Fig. $3[46,47]$. Examples of such hypoxia sensitive polymer include 2-nitroimidazole, a hypoxia sensitive polymer that is hydrophobic gets converted to 2-aminoimidazole and becomes hydrophilic due to which it gets dissolved in physiological fluid and release of the drug occurs $[7,8]$.

$\mathrm{H}_{2} \mathrm{O}_{2}$ responsive systems

Novel glucose-responsive drug delivery system comprising GOx as the glucose-responsive enzyme that converts glucose to gluconic acid by utilizing oxygen also produces hydrogen peroxide in the reaction. This hydrogen peroxide remains in the system that raises the concern about the biocompatibility inside our body [44, 45]. However, this hydrogen peroxide can be used for the dissociation of the glucose-responsive system containing $\mathrm{H}_{2} \mathrm{O}_{2}$ responsive polymer such as co-block polymer polyethylene glycol (PEG) and phenylboronic ester (PBE)-conjugated polyserine (designated $\mathrm{mPEG}-\mathrm{b}-\mathrm{P}[\mathrm{Ser}-\mathrm{PBE}]$ ) for the formation of the system [9]. 
Di-block copolymer employed for the glucose-responsive release comprises polymer containing $\mathrm{H}_{2} \mathrm{O}_{2}$ sensitive PBA pinacol ester that gets hydrolyzed in the presence of hydrogen peroxide formed during the conversion of glucose to gluconic acid $[38,39]$. These polymers become water-soluble after hydrolysis and get dissolved in the physiological fluid causing the release of insulin as shown in Fig. 4. Many such polymers were used for the delivery of drugs-like diblock copolymer (mPEG-b-polyserine) [9], self-assembled polymeric vesicle from a triblock copolymer containing PEG, poly(PBA) (PPBA, glucosesensitive block), and (PPBA pinacol ester) [10], and block copolymer PEG-b-PAPBE [11].

\section{GBP BASED MECHANISM (CONCANAVALIN A-COMPLEX)}

Recently, the glucose-binding capacities of glucose transporter, GBPs, and aptamer have moreover developed within the domain of glucosesensing and insulin delivery systems. As depicted in Fig. 5. concanavalin A can bind specifically, reversibly and competitively to glucose and mannose molecule with high affinity. Concanavalin A can bind specifically, reversibly, and competitively to glucose and mannose molecules with a high affinity. Concanavalin A molecule can bind to the saccharide moiety and act as a cross-linker of macromolecule. Gels are a highly suitable type of formulation that can be used as a glucose-responsive system with Concanavalin A based insulin release. In the presence of increased glucose concentration Concanavalin A binds competitively with the free glucose moiety causing decrease in the crosslinking thickness of the gel [1]. Various other mechanisms that have been used for concanavalin A based insulin delivery are:

Responsive hydrogel cross-linked by Con A

The glucose-responsive moiety Concanavalin A in such a system acts as a cross-linker with the saccharide polymer to form a hydrogel. These concanavalin A moiety competitively binds with the free glucose group present in the body fluid causing gel to sol transformation and swelling of the polymeric system for the release of insulin.

Many such concanavalin A and polymeric complex have been used to formulate a system for glucose-responsive insulin delivery like complex formation between poly (glucosyloxyethy1 methacrylate) (poly[GEMA]) and Con. A [12], (Con A-copolymerized GEMA hydrogel by copolymerizing a monomer having pendant glucose with chemicallymodified ConA having vinyl groups [13]. Allyl glucose copolymerized with acrylamide and crosslinked with concanavalin A. (Obaidat et al. 1996) Glucosyl-oxyethyl acrylate-Chitosan cross-linked with Concanavalin A [15]. ConA@poly(NIPAM) is comprised Concanavalin
$\mathrm{A}$, as the glucose recognition moiety, which is interpenetrated in a chemically-crosslinked network of poly( $\mathrm{N}$-isopropyl acrylamide) (poly[NIPAM]) [16]. Many such concanavalin A based system are mentioned in Table 2.

\section{Irresponsive gel immobilized with Con A}

Concanavalin A reactivity toward d-mannose and d-glucose is much stronger as compared to other polysaccharide rings. This property of concanavalin A causes it to form competitive bonding with free glucose present in blood and causes dissociation of the polymeric complex of the vesicle to release insulin. However, this system is vulnerable to component loss, especially Con A loss, which could lead to weak glucose sensitivity and undesirable biocompatibility. Therefore, it is necessary to develop an efficiently crosslinked network and covalently immobilize Con A to the polymer matrix.

Therefore covalently bonded and efficiently crosslinked concanavalin A with the polysaccharide polymer is an effective method to prevent the leakage of concanavalin A. Researchers used different chemical modifications of Concanavalin A to immobilize it on the polymer-like concanavalin A covalently bounded on hydrogel using carbodiimide reaction, ring-opening reaction, and Schiff base reaction [17], an acrylic derivative of dextran was photo-polymerized with concanavalin A with the help of UV light to form cross-linkage [18]. Concanavalin A was covalently bonded to periodate oxidized dextran [19].

\section{Endogenous lectin-targeted systems}

Recently, glucose responsive insulin delivery systems have been developed by targeting mannose receptor C-type I, a lectin receptor that

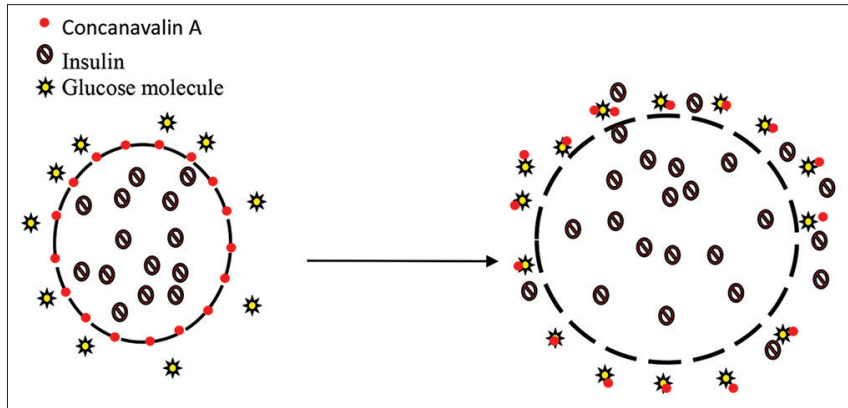

Fig. 5: Schematic representation of competitive binding of Concanavalin A with glucose and swelling of polymeric vesicle to release insulin

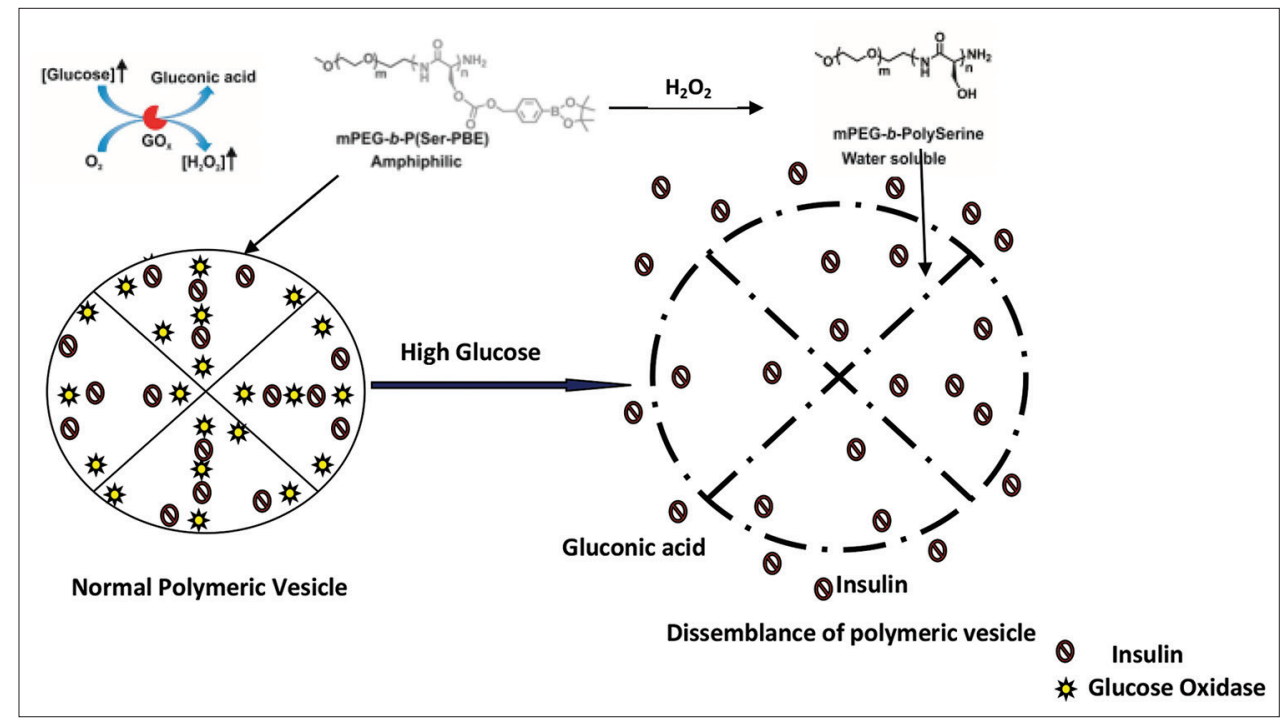

Fig. 4: Schematic representation of $\mathrm{H}_{2} \mathrm{O}_{2}$ responsive release of insulin 
Table 1: Glucoresponsive insulin delivery system based on glucose oxidase

\begin{tabular}{|c|c|c|c|c|c|}
\hline $\begin{array}{l}\text { Bioresponsive } \\
\text { system }\end{array}$ & Component & $\begin{array}{l}\text { Route of } \\
\text { administration }\end{array}$ & In vitro study & In vivo & Reference \\
\hline $\begin{array}{l}\text { Microneedles } \\
\text { patch }\end{array}$ & $\begin{array}{l}\text { Polymeric carrier positively } \\
\text { charged amphiphilic diblock } \\
\text { copolymer } \\
\text { Enzyme } \\
\text { Catalase } \\
\text { Glucose Oxidase }\end{array}$ & Topical & $\begin{array}{l}\text { Average size: } 60 \mathrm{~nm} \\
\zeta \text {-potential: } 4.4 \pm 0.5 \mathrm{mV} \\
\text { Loading capacity: } 50 \mathrm{wt} \% \\
\text { Release rate: twofold faster } \\
\text { at a glucose concentration } \\
\text { of } 400 \mathrm{mg} \mathrm{dL}^{-1} \text { than that of } \\
100 \mathrm{mg} \mathrm{dL}^{-1}\end{array}$ & $\begin{array}{l}\text { Lowering of Blood glucose } \\
\text { levels by } 100 \mathrm{mg} \mathrm{dL}^{-1} \text { in } 30 \\
\text { min post-administration } \\
\text { and maintained below } \\
200 \mathrm{mg} \mathrm{dL}^{-1} \text { for almost } \\
4 \mathrm{~h} \text {, considerably longer } \\
\text { than those of the mice } \\
\text { subcutaneously injected } \\
\text { with insulin }\end{array}$ & [1] 2018 \\
\hline Liposome & $\begin{array}{l}\text { Lipid carrier } \\
\text { hyaluronic acid (HA) } \\
\text { Organic Reagent: } \\
\text { Phenylboronic acid }\end{array}$ & Oral & $\begin{array}{l}\text { Average size : } 94 \mathrm{~nm} \\
\text { zeta potential: }-6.6 \text { to }-28.1 \mathrm{mV} \\
\text { encapsulation efficiency } \\
\text { (EE): } 20.7 \% \\
\text { loading capacity (LC): } 17.1 \%\end{array}$ & $\begin{array}{l}\text { Lowering of Blood glucose } \\
\text { levels during the first } 12 \mathrm{~h} \\
\text { after treatment }\end{array}$ & [2] 2019 \\
\hline $\begin{array}{l}\text { Metal-organic } \\
\text { framework } \\
\text { (MOF) integrated } \\
\text { nanoparticles }\end{array}$ & $\begin{array}{l}\text { Polymeric carrier: zeolitic } \\
\text { imidazole framework-8 (Zinc } \\
\text { nitrate hexahydrate[Zn[NO3]2 } \\
\text { - 6H20], 2- ethylimidazole) } \\
\text { Enzyme: Glucose oxidase }\end{array}$ & $\begin{array}{l}\text { Subcutaneous } \\
\text { route }\end{array}$ & $\begin{array}{l}\text { Average size: } 320 \mathrm{~nm} \\
\text { Release Rate: } 300 \mu \mathrm{g} \mathrm{mL} \mathrm{m}^{-1} \\
\text { insulin release at glucose conc } \\
400 \mathrm{mg} \mathrm{mL}^{-1} \\
\text { Structure degradation was } \\
\text { observed in ZIF@Ins\&GOx but } \\
\text { no degradation in the structure } \\
\text { of ZIF@Ins structure }\end{array}$ & $\begin{array}{l}\text { ZIF@Insu\&GOx reduced } \\
\text { BGL in } 1.5 \mathrm{~h} \text { and maintained } \\
\text { Normoglycemic condition } \\
\left(<200 \mathrm{mg} \mathrm{dL}^{-1}\right) \text { for } 3 \text { days } \\
\text { Free insulin reduced BGL } \\
\text { in } 0.5 \mathrm{~h} \text { but returned } \\
\text { to hyperglycemic } \\
\left(>400 \mathrm{mg} \mathrm{dL}^{-1}\right) \text { with } 24 \mathrm{~h} \\
\text { ZIF@Ins reduced BGL in } \\
2 \mathrm{~h} \text { but recovered above } \\
200 \mathrm{mg} \mathrm{dL}^{-1} \text { within } 24 \mathrm{~h}\end{array}$ & [4] 2020 \\
\hline Peptide hydrogel & $\begin{array}{l}\text { Polymeric carrier: Self- } \\
\text { assembling peptide hydrogel } \\
\text { (peptide IA 0). } \\
\text { Enzyme: Glucose oxidase } \\
\text { Catalase }\end{array}$ & $\begin{array}{l}\text { Subcutaneous } \\
\text { route }\end{array}$ & $\begin{array}{l}\text { Release Rate: } \\
\text { The release rate of insulin } \\
\text { increase to } 4 \text { fold in glucose- } \\
\text { responsive hydrogel as } \\
\text { compared to a normal } \\
\text { hydrogel }\end{array}$ & $\begin{array}{l}\text { BGL decreased in hydrogel } \\
\text { without enzyme G (I) in the } \\
\text { first } 3 \text { h up to } 9 \mathrm{~h} \\
\text { A sharp decrease in BLG } \\
\text { decrease in the hydrogel } \\
\text { with enzyme G (I+E) and } \\
\text { normoglycemic condition } \\
\text { (<11 mmol/L) was } \\
\text { maintained for } 4 \text { days. }\end{array}$ & [5] 2017 \\
\hline $\begin{array}{l}\text { Hyaluronic acid } \\
\text { microgels }\end{array}$ & $\begin{array}{l}\text { Polymeric Carrier: } \\
\text { Hydrophobic m-dextran } \\
\text { Enzyme: Glucose Oxidase } \\
\text { Catalase }\end{array}$ & $\begin{array}{l}\text { Subcutaneous } \\
\text { route }\end{array}$ & $\begin{array}{l}\text { Particle size: } \\
226.9 \pm 20.6 \mathrm{~nm} \\
\text { Loading capacity: } \\
9.1 \pm 0.2 \mathrm{wt} \% \\
\text { Encapsulation efficiency: } \\
66.8 \pm 7.2 \mathrm{wt} \% \text {. } \\
\text { Release rate: } \\
\text { Insulin release increased } \\
\text { to } 2.3 \text { folds when glucose } \\
\text { concentration increased from } \\
100 \mathrm{mg} \mathrm{dL}^{-1} \text { to } 400 \mathrm{mg} \mathrm{dL}^{-1}\end{array}$ & $\begin{array}{l}\text { Diabetic mice treated with } \\
\text { HA(I+E), HA(I), and insulin. } \\
\text { HA(I+E) maintained } \\
\text { normoglycemic condition } \\
\text { in mice for } 8 \text { days, HA(I) } \\
\text { maintained normoglycemic } \\
\text { condition for only } 1 \text { day } \\
\text { due to burst release } \\
\text { whereas in case of insulin } \\
\text { injection BGL returned to } \\
\text { hyperglycemic condition } \\
\text { within } 12 \mathrm{~h}\end{array}$ & [6] 2015 \\
\hline
\end{tabular}


Table 1: (Continued)

\begin{tabular}{|c|c|c|c|c|c|}
\hline $\begin{array}{l}\text { Bioresponsive } \\
\text { system }\end{array}$ & Component & $\begin{array}{l}\text { Route of } \\
\text { administration }\end{array}$ & In vitro study & In vivo & Reference \\
\hline $\begin{array}{l}\text { Multiresponsive } \\
\text { supramolecular } \\
\text { Theranostic } \\
\text { Nanoparticles }\end{array}$ & $\begin{array}{l}\text { Polymeric carrier: } \\
\text { Water-soluble pillar [5] arene. } \\
\text { Enzyme: } \\
\text { Glucose oxidase } \\
\text { Phenyl boronic acid } \\
(-35.13 \mathrm{mV})\end{array}$ & $\begin{array}{l}\text { Intraperitonial } \\
\text { route }\end{array}$ & $\begin{array}{l}\text { Particle Diameter: } \\
210 \text { to } 250 \mathrm{~nm} \\
\text { Zeta potential: } \\
-35.13 \mathrm{mV} \\
\text { Loading Efficiency: } \\
59.60 \% \\
\text { Release Rate: } \\
5 \% \text { release occurred in } \\
\text { euglycemic condition } \\
\left(100 \mathrm{mg} \mathrm{dL}^{-1} \text { glucose }\right. \\
\text { concentration) } \\
40 \% \text { release occurred in } \\
\text { Glucose conc } 250 \mathrm{mg} \mathrm{dL}^{-1} \\
\text { The release was much } \\
\text { higher when vesicles were } \\
\text { incubated at much higher conc } \\
400 \mathrm{mg} \mathrm{dL}^{-1}\end{array}$ & $\begin{array}{l}\text { Free insulin }(\mathrm{I}) \text { and Vesicle } \\
\text { with enzyme }(\mathrm{V}[\mathrm{E}+\mathrm{I})] \\
\text { and insulin reduced } \mathrm{BGL} \\
\text { in } 0.5 \mathrm{~h} \\
\text { Normoglycemic state } \\
\text { maintained by }(\mathrm{V}[\mathrm{E}+\mathrm{I}]) \\
\text { for } 2 \mathrm{~h}\end{array}$ & [7] 2018 \\
\hline $\begin{array}{l}\text { Hypoxia and } \mathrm{H}_{2} \mathrm{O}_{2} \\
\text { Dual-Sensitive } \\
\text { Vesicles }\end{array}$ & $\begin{array}{l}\text { Polymeric Carrier: } \\
\text { Di block co-polymer PEG } \\
\text { and polyserine modified } \\
\text { with 2-nitroimidazole (PEG- } \\
\text { polyserine) } \\
\text { Enzyme: } \\
\text { Glucose Oxidase } \\
\text { Catalase }\end{array}$ & $\begin{array}{l}\text { Transcutaneous } \\
\text { patch }\end{array}$ & $\begin{array}{l}\text { Average diameter: } \\
94 \mathrm{~nm} \text { found by DSC } \\
\text { Loading efficiency: } \\
3.2 \% \\
\text { Release rate: } \\
\text { Quick insulin release occurred } \\
\text { in high glucose concentration } \\
\left(400 \mathrm{mg} \mathrm{dL}^{-1}\right) \text { as compared } \\
\text { to low glucose concentration } \\
\left(100 \mathrm{mg} \mathrm{dL}^{-1}\right) \text {. } \\
\text { Insulin release found to } \\
\text { be } 11.2 \text { fold increase in } \\
\text { high glucose concentration } \\
\left(400 \mathrm{mg} \mathrm{dL}^{-1}\right) \text { as compared } \\
\text { to low glucose concentration } \\
\left(100 \mathrm{mg} \mathrm{dL}^{-1}\right)\end{array}$ & $\begin{array}{l}\text { d-GRP }(E+I) \text { containing } \\
\text { enzyme and insulin caused } \\
\text { a rapid decrease in BGL } \\
\text { within } 1 \mathrm{~h} \text { of administration } \\
\text { and normal glycemic } \\
\text { condition was maintained } \\
\text { for } 6 \mathrm{~h} \\
\text { No decrease was observed } \\
\text { in BGL with MNs without } \\
\text { enzyme (d-GRP [I]) and } \\
\text { they remained stable for } \\
24 \mathrm{~h}\end{array}$ & [8] 2017 \\
\hline $\begin{array}{l}\text { PLGA/ } \\
\text { Chitosan based } \\
\text { nanocomplex }\end{array}$ & $\begin{array}{l}\text { Polymeric carrier: Chitosan } \\
\text { and PLGA (Poly lactic co } \\
\text { glycolic acid) } \\
\text { Enzymes: } \\
\text { Glucose oxidase } \\
\text { Catalase enzyme }\end{array}$ & $\begin{array}{l}\text { Subcutaneous } \\
\text { route }\end{array}$ & 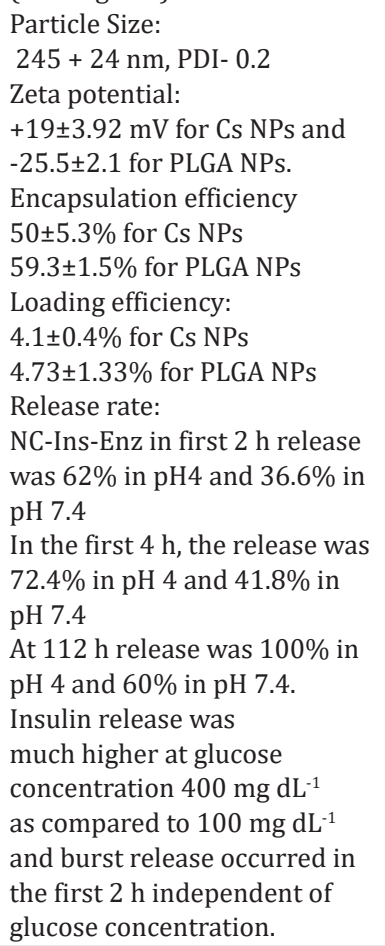 & $\begin{array}{l}\text { Ins SC reduced BGL to } 100 \\
\mathrm{mg} \mathrm{dL}^{-1} \text { and returned to } \\
400 \mathrm{mg} \mathrm{dL}^{-1} \text { after } 8 \mathrm{~h} \\
\mathrm{Cs}-\mathrm{Ins}-2 \mathrm{mg} \text { and Cs-Ins- } 4 \mathrm{mg} \\
\text { reduced BGL for } 12 \mathrm{~h} \text { and } \\
24 \mathrm{~h} \\
\mathrm{NC}-\mathrm{Ins}-2 \mathrm{mg} \text { and NC-Ins- } \\
4 \mathrm{mg} \text { reduced BGL for } 48 \mathrm{~h} \\
\text { and } 72 \mathrm{~h}\end{array}$ & [9] 2019 \\
\hline
\end{tabular}


Table 1: (Continued)

\begin{tabular}{|c|c|c|c|c|c|}
\hline $\begin{array}{l}\text { Bioresponsive } \\
\text { system }\end{array}$ & Component & $\begin{array}{l}\text { Route of } \\
\text { administration }\end{array}$ & In vitro study & In vivo & Reference \\
\hline $\begin{array}{l}\text { Glucose } \\
\text { responsive micro- } \\
\text { devices }\end{array}$ & $\begin{array}{l}\text { Carrier: } \\
\text { PDMS (polydimethylsiloxane) } \\
\text { Enzyme: } \\
\text { Glucose oxidase } \\
\text { Catalase }\end{array}$ & $\begin{array}{l}\text { Intraperitonial } \\
\text { implants }\end{array}$ & $\begin{array}{l}\text { Insulin release rate increase } \\
\text { in } 2.5 \mathrm{~h} \text { when glucose } \\
\text { concentration increased from } \\
5 \mathrm{mmol} \mathrm{L}^{-1} \text { to } 20 \mathrm{mmol} \mathrm{L}^{-1} \text {. } \\
49.7+11.1 \mu \mathrm{g} \text { amount of insulin } \\
\text { released in } 4 \mathrm{~h}\end{array}$ & $\begin{array}{l}\text { Normoglycemia was } \\
\text { maintained in the group } \\
\text { implanted with hydrogel } \\
\text { for } 7 \text { days and BGL increase } \\
\text { after day } 10\end{array}$ & [10] 2012 \\
\hline $\begin{array}{l}\text { Microneedle-array } \\
\text { patches }\end{array}$ & $\begin{array}{l}\text { Polymeric Carrier: } \\
\text { Hyaluronic acid + 2- } \\
\text { nitroimidazole } \\
\text { Enzymes: } \\
\text { Glucose oxidase }\end{array}$ & $\begin{array}{l}\text { Transcutaneous } \\
\text { patch }\end{array}$ & $\begin{array}{l}\text { Insulin release rate increased } \\
\text { to } 6.6 \text { times when glucose } \\
\text { conc increased from } 100 \text { to } \\
400 \mathrm{mg} \mathrm{dL}^{-1} \text { in } 20 \text { min. } \\
\text { Whereas GRVs containing } \\
\text { half amount of GOx showed } \\
\text { slow release of insulin due to } \\
\text { a decrease in consumption } \\
\text { of oxygen for conversion of } \\
\text { glucose to gluconic acid. }\end{array}$ & $\begin{array}{l}\text { Insulin dose was } 10 \mathrm{mg} / \mathrm{kg} \text {. } \\
\text { BGL reduced to } 200 \mathrm{mg} \mathrm{dL}^{-1} \\
\text { and maintained }<200 \mathrm{mg} \\
\mathrm{dL}^{-1} \text { for } 4 \text { h by } \mathrm{GRV}(\mathrm{I}+\mathrm{E}) \text {. } \\
\mathrm{BGL} \text { reduced to } 350 \mathrm{mg} \\
\mathrm{dL}^{-1} \text { with } \mathrm{GRV} \text { with half } \\
\text { enzyme concentration. } \\
\text { GRV without enzyme did } \\
\text { not show any decrease in } \\
\text { BGL. }\end{array}$ & [11] 2015 \\
\hline $\begin{array}{l}\text { Erythrocyte- } \\
\text { Membrane- } \\
\text { Camouflaged } \\
\text { Nanoparticles }\end{array}$ & $\begin{array}{l}\text { Polymeric carrier: } \\
\text { RBC membrane, } \\
\text { Ethoxy acetal derivatized } \\
\text { dextran } \\
\text { Enzymes: } \\
\text { Glucose oxidase } \\
\text { Catalase }\end{array}$ & $\begin{array}{l}\text { Intravenous } \\
\text { injection }\end{array}$ & $\begin{array}{l}\text { Particle size: } 124.3 \mathrm{~nm} \\
\text { Zeta potential: } \\
-10.4 \text { to }-20.1 \mathrm{mV} \\
\text { Release rate: } \\
\text { Maximum insulin release } \\
\text { occurred was } 7.8+0.8 \mu \mathrm{g} \text { at } \\
400 \mathrm{mg} \mathrm{dL}^{-1} \text { glucose solution. } \\
\text { And release rate increased } \\
\text { to } 2.9 \text { fold when glucose } \\
\text { concentration increased from } \\
100 \mathrm{mg} \mathrm{dL}^{-1} \text { to } 400 \mathrm{mg} \mathrm{dL}^{-1} \text {. }\end{array}$ & $\begin{array}{l}\text { STZ induced diabetic } \\
\text { mice treated with NP(I), } \\
\mathrm{NP}(\mathrm{I}+\mathrm{E}), \mathrm{RBCm} / \mathrm{NP}(\mathrm{I}+\mathrm{E}) \\
\text { and } \mathrm{RBCmNP}(\mathrm{I}+\mathrm{E}) \text {. } \\
\mathrm{NP}(\mathrm{I}) \text { and NP(I+E) reduced } \\
\text { BGL to hypoglycemic state } \\
\text { within } 1 \mathrm{hr} \text { and returned to } \\
\text { hyperglycemic state within } \\
12 \mathrm{~h} \\
\mathrm{RBCm} / \mathrm{NP}(\mathrm{I}+\mathrm{E}) \text { maintained } \\
\text { normoglycemic condition } \\
\text { for } 4 \mathrm{~h} \\
\mathrm{RBCmNP}(\mathrm{I}+\mathrm{E}) \text { slowly } \\
\text { reduced BGL and } \\
\text { maintained normoglycemic } \\
\text { condition for } 24 \text { h and } \\
\text { returned to hyperglycemic } \\
\text { state slowly over } 4 \text { days }\end{array}$ & [12] 2018 \\
\hline $\begin{array}{l}\text { Glucose- } \\
\text { Responsive } \\
\text { Microgels } \\
\text { Integrated } \\
\text { with Enzyme } \\
\text { nanocapsules }\end{array}$ & $\begin{array}{l}\text { Polymeric carrier: } \\
\text { Chitosan } \\
\text { Enzyme: } \\
\text { Glucose oxidase } \\
\text { catalase }\end{array}$ & $\begin{array}{l}\text { Subcutaneous } \\
\text { route }\end{array}$ & $\begin{array}{l}\text { Particle size: } \\
256+18 \mu \mathrm{m} \\
\text { Loading efficiency: } \\
44.6+2.8 \% \\
\text { Encapsulation efficiency: } \\
59.7+3.4 \% \\
\text { Release rate: } \\
\text { Insulin release rate increase } \\
\text { to } 2.5 \text { folds when glucose } \\
\text { concentration increased from } \\
100 \mathrm{mg} \mathrm{dL}^{-1} \text { to } 400 \mathrm{mg} \mathrm{dL}^{-1} \\
\text { Particles showed } 1.7 \text { times } \\
\text { increase in diameter and } 5 \mathrm{fold} \\
\text { increase in volume within } 3 \mathrm{~h} \\
\text { of incubation with } 400 \mathrm{mg} \mathrm{dL}^{-1} \text {. } \\
\text { Whereas no swelling occurred } \\
\text { on incubation with } 100 \mathrm{mg} \mathrm{dL}^{-1} \\
\text { glucose concentration }\end{array}$ & $\begin{array}{l}\text { BGL was reduced in mice } \\
\text { treated with MG (I+E) and } \\
\text { MG(I) to normoglycemic } \\
\text { condition within } 2 \mathrm{~h} \text { of } \\
\text { administration through inj } \\
\text { MG (I+E) maintained } \\
\text { normoglycemic condition } \\
\text { for } 12 \mathrm{~h} \text { and then gradually } \\
\text { increased. } \\
\text { Whereas MG (I) showed a } \\
\text { rapid increase in BGL after } \\
2 \mathrm{~h} \text { of administration. }\end{array}$ & [13] 2013 \\
\hline $\begin{array}{l}\text { Glucose } \\
\text { responsive } \\
\text { bioinorganic nano- } \\
\text { hybrid membrane }\end{array}$ & $\begin{array}{l}\text { Polymeric carrier: } \\
\text { poly(Nisopropylacrylamide- } \\
\text { co-methacrylic acid) } \\
\text { (poly[NIPAM-MAA]) } \\
\text { Bovine serum albumin } \\
\text { Enzymes: } \\
\text { Glucose oxidase } \\
\text { Catalase }\end{array}$ & N.A & $\begin{array}{l}\text { Insulin permeability increase } \\
2 \text { and } 4 \text { fold in membrane with } \\
\mathrm{MnO}_{2} \text { when glucose increase } \\
\text { from } 100 \text { to } 200 \mathrm{mg} \mathrm{dL}^{-1} \text { and } \\
100 \text { to } 400 \mathrm{mg} \mathrm{dL}^{-1} \text { respectively } \\
\text { Insulin permeability increase } \\
\text { only } 2 \text { fold in the membrane } \\
\text { without } \mathrm{MnO}_{2} \text { when glucose } \\
\text { increase from } 100 \text { to } \\
400 \mathrm{mg} \mathrm{dL}^{-1}\end{array}$ & N.A & [14] 2010 \\
\hline
\end{tabular}


Table 1: (Continued)

\begin{tabular}{|c|c|c|c|c|c|}
\hline $\begin{array}{l}\text { Bioresponsive } \\
\text { system }\end{array}$ & Component & $\begin{array}{l}\text { Route of } \\
\text { administration }\end{array}$ & In vitro study & In vivo & Reference \\
\hline $\begin{array}{l}\text { Subcutaneous } \\
\text { Implant }\end{array}$ & $\begin{array}{l}\text { Carrier: Micro device } \\
\text { salinized by 3-aminopropyl } \\
\text { trimethoxysilane and } \\
\text { crosslinked with bovine } \\
\text { serum albumin } \\
\text { Enzyme: } \\
\text { Glucose Oxidase }\end{array}$ & Implants & $\begin{array}{l}\text { Release rate: Insulin release } \\
\text { from the micro device } \\
\text { increased } 2.29 \text { times when } \\
\text { glucose concentration } \\
\text { increased from } 100 \mathrm{mg} \mathrm{dL}^{-1} \text { to } \\
400 \mathrm{mg} \mathrm{dL}^{-1}\end{array}$ & & [15] 2015 \\
\hline $\begin{array}{l}\text { Glucose sensitive } \\
\text { liposomes }\end{array}$ & $\begin{array}{l}\text { Polymeric Carrier: } \\
\text { Egg phosphatidylcholine } \\
\text { (EPC) } \\
\text { Enzyme: } \\
\text { P(NIPAM-co-MAA-co-ODA) } \\
\text { conjugated glucose oxidase }\end{array}$ & $\begin{array}{l}\text { Subcutaneous } \\
\text { route }\end{array}$ & $\begin{array}{l}\text { Particle size: } 100-300 \mathrm{~nm} \\
\text { Release rate: When glucose } \\
\text { concentration was } 50 \mathrm{mg} \mathrm{dL}^{-1} \\
\text { insulin release was } 40 \% \text { in } \\
90 \mathrm{~min} \\
\text { When the concentration was } \\
200 \mathrm{mg} \mathrm{dL}^{-1} \text { insulin release } \\
\text { was } 56 \% \text { in } 90 \mathrm{~min}\end{array}$ & N.A & [16] 2009 \\
\hline $\begin{array}{l}\text { Glucose- } \\
\text { Responsive } \\
\text { Micelles }\end{array}$ & $\begin{array}{l}\text { Polymeric carrier: } \\
\text { (PEG-b-PDPA) } \\
\text { Enzyme: } \\
\text { Glucose oxidase }\end{array}$ & N.A & $\begin{array}{l}\text { Particle size: } 328.3 \pm 20.7 \mathrm{~nm} \\
\text { Loading efficiency: } \\
\mathrm{LE}=21.12 \% \text { for insulin } \\
\mathrm{LE}=24.09 \% \text { for GOx } \\
\text { Encapsulation efficiency: } \\
\mathrm{EE}=91.53 \% \text { for insulin } \\
\mathrm{EE}=86.08 \% \text { for GOx } \\
\text { Release Profile: Insulin release } \\
\text { was } 50 \% \text { in absence of glucose } \\
\text { concentration. Whereas } \\
\text { the release was } 80 \% \text { in } \\
\text { presence of } 10 \mathrm{mg} / \mathrm{ml} \text { glucose } \\
\text { concentration }\end{array}$ & N.A & [17] 2016 \\
\hline $\begin{array}{l}\text { Bioresponsive } \\
\text { microneedle with } \\
\text { a Sheath structure }\end{array}$ & $\begin{array}{l}\text { Polymeric carrier: } \\
\text { Poly(DMAEMA-PBA) Enzyme: } \\
\text { Glucose Oxidase }\end{array}$ & Oral & $\begin{array}{l}\text { Release rate: The release } \\
\text { rate of insulin from Ins-NCs } \\
\text { entrapped in the gel was } \\
\text { twofold faster at a glucose } \\
\text { concentration of } 400 \mathrm{mg} \mathrm{dL}^{-1} \\
\text { than that of } 100 \mathrm{mg} \mathrm{dL}^{-1}\end{array}$ & N.A & [18] 2018 \\
\hline $\begin{array}{l}\text { Dextran } \\
\text { nanoparticles }\end{array}$ & $\begin{array}{l}\text { Polymeric carrier: } \\
\text { Nano-acryloyl crosslinked } \\
\text { dextran dialdehyde (NACDD) } \\
\text { Enzyme: } \\
\text { Glucose oxidase }\end{array}$ & $\begin{array}{l}\text { Subcutaneous } \\
\text { route }\end{array}$ & $\begin{array}{l}\text { Particle size: } 48 \mathrm{~nm} \text { to } 74 \mathrm{~nm} \\
\text { Loading Efficiency: } 48.68 \% \\
\text { Release Rate: Release was } \\
\text { found to be } 70 \% \text { in pH } 7.4 \text { with } \\
\text { NACDD, whereas release was } \\
\text { found to be } 90 \% \text { with NACDD- } \\
\text { GOx in pH } 7.4 \text { with a glucose } \\
\text { concentration of } 4 \mathrm{mg} / \mathrm{ml}\end{array}$ & NA & [19] 2019 \\
\hline $\begin{array}{l}\text { Mesoporous silica } \\
\text { nanoparticles }\end{array}$ & $\begin{array}{l}\text { Polymeric carrier: } \\
\text { n-cetyltrimethyl ammonium } \\
\text { bromide (CTAB). } \\
\text { Enzyme: } \\
\beta \text {-cyclodextrin-modified } \\
\text { enzyme glucose oxidase (CD- } \\
\text { GOx) }\end{array}$ & NA & $\begin{array}{l}\text { Particle size: } 426.1 \pm 54.2 \mathrm{~nm} \\
\text { Zeta potential: }-17.7 \mathrm{mV} \\
\text { Release Rate: } 3 \% \text { FITC Insulin } \\
\text { release in } 20 \mathrm{~h} \text { in absence of } \\
\text { glucose } 26 \% \text { insulin released } \\
\text { in solution with } 50 \mathrm{mM} \text { of } \\
\text { glucose }\end{array}$ & NA & [20] 2017 \\
\hline $\begin{array}{l}\text { Self-Assembled } \\
\text { Polyamine } \\
\text { Nanoparticles }\end{array}$ & $\begin{array}{l}\text { Polymeric carrier: } \\
\text { Poly(allylamine } \\
\text { hydrochloride) and Sodium } \\
\text { phosphate monobasic } \\
\text { monohydrate salt aggregate } \\
\text { Enzyme } \\
\text { Glucose oxidase }\end{array}$ & Oral route & $\begin{array}{l}\text { Average size: } 90 \mathrm{~nm} \\
\text { Release rate: } 9 \% \text { release } \\
\text { in absence of glucose, } 15 \% \\
\text { release in normoglycemic } \\
\text { condition }(5 \mathrm{mM}), 40 \% \text { release } \\
\text { in glucose conc }(10 \mathrm{mM}) \\
100 \% \text { release in hyperglycemic } \\
\text { condition }(15 \mathrm{mM} \text { and } 20 \mathrm{mM})\end{array}$ & NA & [21] 2019 \\
\hline
\end{tabular}

is primarily expressed on hepatic sinusoidal endothelial cells, specific macrophages, and dendritic cells for the treatment of hyperglycemia.

Some of the researchers have targeted lectin receptors for the delivery of insulin through the small intestine by conjugating insulin with saccharide conjugate, like mannose conjugated with insulin forming MK-2640 novel insulin delivery that showed glucose-responsive release
[20,21]. Fig. 6 describes the pathway about the delivery of insulin through lectin receptor targeting through small intestine. Disaccharide maltose bound to form semisynthetic sugar-insulin derivative complementary to the binding site of lectin Concanavalin A, where the release of maltose conjugated insulin release is proportional to the amount of glucose concentration present in the blood [22]. 
Table 2: Glucoresponsive insulin delivery system based on Concanavalin A

\begin{tabular}{|c|c|c|c|c|c|}
\hline $\begin{array}{l}\text { Bioresponsive } \\
\text { system }\end{array}$ & Component & $\begin{array}{l}\text { Route of } \\
\text { administration }\end{array}$ & In vitro study & In vivo & Reference \\
\hline Microhydrogel & $\begin{array}{l}\text { Polymeric carriers: Glycidyl } \\
\text { methacrylate modified dextran } \\
\text { Enzyme: Ethylene glycol } \\
\text { acrylate methacrylate modified } \\
\text { concanavalin A }\end{array}$ & Oral & $\begin{array}{l}\text { The release rate of insulin from Ins-NCs } \\
\text { entrapped in the gel was twofold faster at a } \\
\text { glucose concentration of } 400 \mathrm{mg} \mathrm{dL}^{-1} \text { than that of } \\
100 \mathrm{mg} \mathrm{dL}^{-1}\end{array}$ & NA & [29] 2018 \\
\hline Microgels & $\begin{array}{l}\text { Polymeric carrier: Chitosan, } \\
\text { Methyl } \\
\alpha \text {-d-glucopyranoside } \\
\text { Enzyme: Concanavalin A }\end{array}$ & Oral & $\begin{array}{l}\text { Particle size : } 2.9 \pm 1.0 \\
\text { Encapsulation efficiency (EE): } 61.7 \% \text { at } \mathrm{pH} 7.4 \\
\text { loading capacity (LC): } 6.7 \% \text { at } \mathrm{pH} 7.4 \\
\text { Release Rate: The release of insulin was found to be } \\
\text { much higher in presence of glucose as compared to } \\
\text { a solution without glucose. Even glucose-responsive } \\
\text { insulin release was able to release insulin to longer } \\
\text { extend }\end{array}$ & NA & [30] 2014 \\
\hline Nanoparticles & $\begin{array}{l}\text { Polymeric carrier: } \\
\text { Gelatinized Amylopectin } \\
\text { Enzymes: } \\
\text { Concanavalin A }\end{array}$ & Oral & $\begin{array}{l}\text { Particle Size: } 241.10-292.20 \mathrm{~nm} \\
\text { Encapsulation efficiency: } 69.73 \% \text {. } \\
\text { Loading capacity: } 17 \% \text {. } \\
\text { insulin-release rate for nanoparticles in } 3 \mathrm{mg} / \mathrm{ml} \\
\text { Release study: Concanavalin A containing } \\
\text { nanoparticles shows a much higher release due to } \\
\text { more conjugation of glucose with concanavalin A as } \\
\text { compared to nanoparticles without enzymes }\end{array}$ & NA & [31] 2018 \\
\hline Microhydrogel & $\begin{array}{l}\text { Polymeic carrier } \\
\text { Glucosyloxyethyl methacrylate } \\
\text { (GEMA) } \\
\text { N-(2-[dimethylamino] ethyl)- } \\
\text { methacrylamide (DMAEMA) } \\
\text { Enzyme } \\
\text { Concanavalin A }\end{array}$ & Oral & $\begin{array}{l}\text { Particle Size: } 38 \mu \mathrm{m} \\
\text { Release rate: Release of insulin from concanavalin } \\
\text { A based microhydrogel show an increase in release } \\
\text { rate with an increase in glucose concentration in the } \\
\text { release medium }\end{array}$ & NA & [32] 2011 \\
\hline Microparticles & $\begin{array}{l}\text { Polymeric carrier: } \\
\text { Chitosan, Dextran } \\
\text { Enzyme: Concanavalin A }\end{array}$ & Oral & $\begin{array}{l}\text { Particle Size: } \\
2.5 \mu \mathrm{m} \text {, Entrapment efficiency: } 92.2 \% \text {, } \\
\text { Loading capacity: } 9.1 \% \\
\text { Release rate: A slower release rate of insulin was } \\
\text { detected in PBS (pH 7.4) with glucose } 0 \mathrm{mg} / \mathrm{mL} \\
\text { when compared with that in PBS (pH 7.4) with } \\
\text { glucose } 4 \mathrm{mg} / \mathrm{mL} \text {. However, a burst release profile } \\
\text { within the first } 20 \text { min was displayed in both } \\
\text { mediums }\end{array}$ & NA & [34] 2010 \\
\hline Microspheres & $\begin{array}{l}\text { Polymeric carrier: Dextran } \\
\text { conjugated glycidyl } \\
\text { methacrylate } \\
\text { Enzyme: Concanavalin A }\end{array}$ & & $\begin{array}{l}\text { Particle size: } 5.23 \mu \mathrm{m} \\
\text { Entrapment Efficiency: } 94.6 \% \\
\text { Loading capacity: } 12.13 \% \\
\text { Release rate: Effect of light radiation was observed } \\
\text { on the release rate of insulin. The light-irradiation } \\
\text { could significantly reduce the average insulin release } \\
\text { rate in the first cycle of bolus-basal release after } \\
\text { the implementation of the first two times of light- } \\
\text { irradiation, while no significant change happens on } \\
\text { the third and fourth light-irradiation, which were } \\
\text { attributed to the less remnant un-reacted photo- } \\
\text { active groups and relatively high remained insulin } \\
\text { concentration of irradiated samples compared with } \\
\text { non-irradiated microspheres }\end{array}$ & NA & [35] 2019 \\
\hline Hydrogel & $\begin{array}{l}\text { Polymeric carrier: } \\
\text { Methacrylated dextran (Dex-G) } \\
\text { Enzyme: Concanavalin A }\end{array}$ & Oral & NA & NA & [36] 2010 \\
\hline
\end{tabular}

\section{Glucose transporter-mediated insulin delivery}

Recently many researchers have conceived the concept to use glucose transporter (Glut) to achieve glucose-responsive insulin release from the formulation for the mitigation of hyperglycemic conditions. In such type of release system, insulin is reversibly bound with glucose transporter present on the cells, and insulin is released mediated by the displacement of insulin from the glucose transporter due to competitive binding of free glucose present in the blood under hyperglycemia conditions.
Some of such formulations maneuvered by the researcher were conjugating insulin reversibly with Glut inhibitor. On reaching to blood circulation in hyperglycemic condition insulin analog-Glut complexes dissociate. The free insulin analog can subsequently bind to IR to trigger the translocation of Glut to cell membranes and enhance glucose clearance into muscle and fat. Meanwhile, the Glut, which is previously inaccessible to glucose as part of the insulin analog-Glut complex, can enhance the blood glucose clearance [23-25] formulated insulin $\mathrm{F}$ by conjugation of human recombinant insulin and glucose transporter 
Table 3: Glucoresponsive insulin delivery system based on phenyl boronic acid

\begin{tabular}{|c|c|c|c|c|c|}
\hline Bioresponsive system & Component & $\begin{array}{l}\text { Route of } \\
\text { administration }\end{array}$ & In vitro study & In vivo & Reference \\
\hline $\begin{array}{l}\text { Double-layered } \\
\text { nanogel }\end{array}$ & $\begin{array}{l}\text { Polymeric carrier: glycol } \\
\text { chitosan (GC)/sodium } \\
\text { alginate (SA)- poly(L- } \\
\text { glutmate-co-N-3-L- } \\
\text { glutamylphenylboronic } \\
\text { acid) (PGGA) } \\
\text { Enzyme: Phenyl boronic } \\
\text { acid }\end{array}$ & $\begin{array}{l}\text { Retro-orbital } \\
\text { route }\end{array}$ & $\begin{array}{l}\text { Particle Size: } 767.9 \mathrm{~nm} \\
\text { Zeta potential: } 5-12 \mathrm{mV} \\
\text { Loading efficiency: } 71+3.5 \% \\
\text { Release rate: Insulin release } \\
\text { from PBA conjugated } \\
\text { nanogel showed increased } \\
\text { release in insulin with the } \\
\text { release medium containing } \\
\text { glucose conc of } 5 \mathrm{mg} / \mathrm{ml} \text { and } \\
\text { 10mg/ml. The release was } \\
\text { much higher as compared to } \\
\text { the glucose conc with } 0 \mathrm{mg} / \\
\text { ml and } 1 \mathrm{mg} / \mathrm{ml}\end{array}$ & $\begin{array}{l}\text { To confirm the controlled } \\
\text { insulin release capability of GC/ } \\
\text { SA-PGGA nanogel in vivo, mice } \\
\text { were treated with four different } \\
\text { samples: blank GC/SA-PGGA, } \\
\text { free insulin, insulin loaded GC/ } \\
\text { SA, and insulin-loaded GC/ } \\
\text { SA-PGLA. } \\
\text { Compared to insulin-loaded GC/ } \\
\text { SA, insulin-loaded GC/SA-PGGA- } \\
\text { treated mice showed that the } \\
\text { blood glucose levels were more } \\
\text { dramatically decreased until } 60 \\
\text { min, meaning that GC/SA-PGGA } \\
\text { nanogel can controllably release } \\
\text { the encapsulated insulin by its } \\
\text { glucose responsiveness }\end{array}$ & [33] 2015 \\
\hline $\begin{array}{l}\text { Glucose-responsive } \\
\text { insulin activity by } \\
\text { covalent modification } \\
\text { with aliphatic } \\
\text { phenylboronic acid } \\
\text { conjugates }\end{array}$ & $\begin{array}{l}\text { Polymeric carrier: } \mathrm{m} \\
\text { 12-amino dodecanoic } \\
\text { acid } \\
\text { Enzyme: Phenyl boronic } \\
\text { acid }\end{array}$ & Oral & NA & NA & [59] 2015 \\
\hline Nanoparticles & $\begin{array}{l}\text { Polymeric carrier: } \\
\text { Cyclodextrin conjugated } \\
\text { with (5-ethyl-2-phenyl- } \\
\text { 1,3,2-dioxaborinan-5-yl) } \\
\text { methyl 2-bromoacetate } \\
\text { (EPDMB) } \\
\text { Enzyme: Phenyl boronic } \\
\text { acid }\end{array}$ & Oral & $\begin{array}{l}\text { Release rate: Insulin } \\
\text { release from nanoparticles } \\
\text { formed by the conjugation } \\
\text { of cyclodextrin with } \\
\text { phenylboronic acid showed } \\
\text { increased release of insulin } \\
\text { in presence of glucose } \\
\text { concentration as compared } \\
\text { to the nanoparticles without } \\
\text { phenylboronic acid }\end{array}$ & NA & [58] 2018 \\
\hline Microparticles & $\begin{array}{l}\text { Polymeric carrier: A } \\
\text { pseudopolyrotaxane } \\
\text { (PPRX) comprising } \\
\text { 3-carboxy-5-nitro } \\
\text { phenylboronic acid } \\
\text { modified } \gamma \text {-cyclodextrin } \\
\text { (NPBA- } \gamma \text {-CyD) } \\
\text { Enzyme: Phenyl boronic } \\
\text { acid }\end{array}$ & Oral & NA & NA & [60] 2016 \\
\hline Polymeric complex & $\begin{array}{l}\text { Polymeric carrier: } \\
\text { Polymerized tert-butyl } \\
\text { (2-acrylamido ethyl) } \\
\text { carbamate (Boc-EDAA) } \\
\text { Enzyme: Phenyl boronic } \\
\text { acid }\end{array}$ & Sub-cutaneous & $\begin{array}{l}\text { Release rate: Poly (EDAA0.7- } \\
\text { FPBA0.3) -insulin complex } \\
\text { exhibited a relatively } \\
\text { slow insulin release rate. } \\
\text { Moreover, the insulin release } \\
\text { rate was steadily increased } \\
\text { in response to glucose } \\
\text { concentration variation } \\
\text { (from } 100 \text { to } 400 \text { mg/dl), } \\
\text { achieving a maximum of } \\
\text { fourfold enhancement } \\
\text { Poly (EDAA0.4-FPBA0.6) } \\
\text {-insulin complex also } \\
\text { achieved pulsatile insulin } \\
\text { release for several cycles } \\
\text { by alternating glucose } \\
\text { concentrations between } 100 \\
\text { and } 400 \text { mg/dl }\end{array}$ & $\begin{array}{l}\text { Poly (EDAA0.7-FPBA0.3), Poly } \\
\text { (EDAA0.4-FPBA0.6), a dose } \\
\text { of } 80 \text { U/kg was administered. } \\
\text { The BGLs of all treated groups } \\
\text { decreased to below } 200 \mathrm{mg} / \\
\text { dl, indicating the retention of } \\
\text { activity of complex insulin. } \\
\text { Moreover, Poly (EDAA0.4- } \\
\text { FPBA0.6), was shown to } \\
\text { maintain BGLs within the } \\
\text { normal range (<200 mg/dl) for } \\
8 \text { h, much longer than native } \\
\text { insulin and Poly (EDAA0.7- } \\
\text { FPBA0.3) }\end{array}$ & [61] 2019 \\
\hline
\end{tabular}

BGL: Blood glucose level, MNs: Micro needle, d-GRPs: Dual sensitive, glucose sensitive polymersomes, P(NIPAM-co-MAA-co-ODA): Poly(N-isopropylacrylamide-comethacrylic acid-co-octadecylacrylate), Poly(DMAEMA-PBA): poly(2-dimethylaminoethyl methacrylate)-block-poly(n-butyl acrylate) (PDMAEMA-b-PBA) 


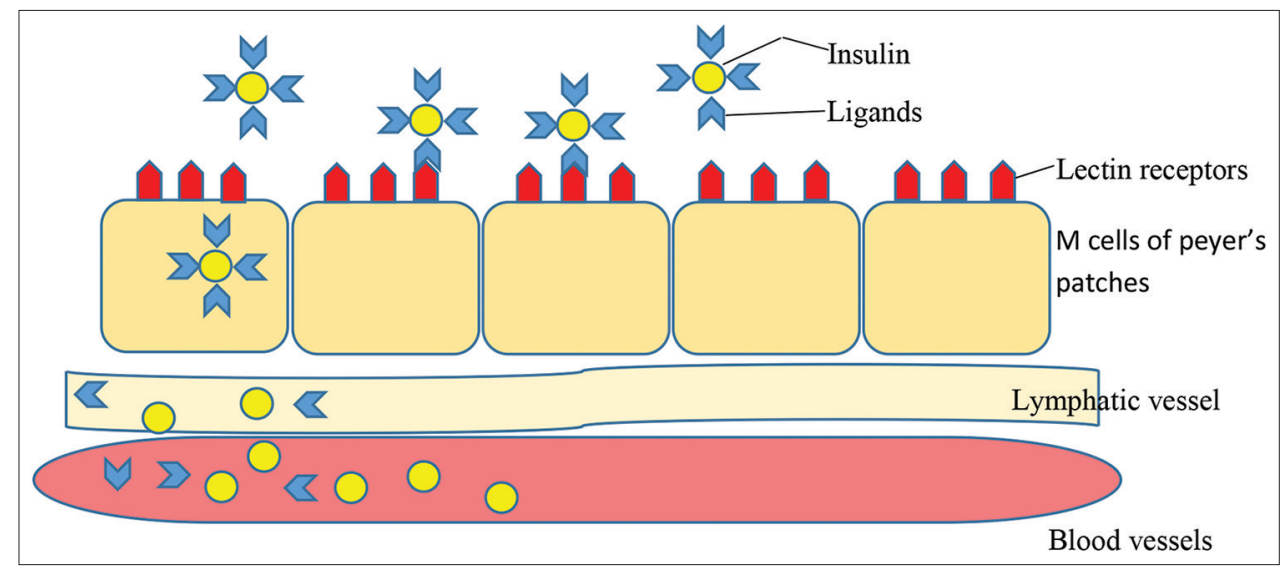

Fig. 6: Schematic representation of ligand target insulin delivery system

inhibitor, forskolin. The introduction of forskolin reduces the water solubility of insulin and prolongs its retention after subcutaneous injections, thereby providing sustained release of insulin-F from the injected depot.

\section{PBA}

Various researchers have extensively studied the use of GOx and GBP for the formulation of glucose-responsive insulin delivery system; however, as compared to GOx and GBP-like concanavalin A, PBA is a highly stable glucoseresponsive compound with high durability in the physiological environment [26]. Demonstrated the formation of an ester from aromatic boronic acids and a series of diol-containing compounds. It was subsequently found that a cis-1, 2- or 1, 3-diol compound favored the formation of esters with PBA. PBA found reversible complexation with other polymeric compounds that disrupt in presence of glucose concentration causing the release of insulin from the polymeric vesicles [37].

Different types of systems such as bulk hydrogels, micro/nanogels, and self-assembled micelles can be prepared from molecules with a PBA moiety or boronate ester. An increase in glucose concentration in physiological fluid dissociates the PBA- diol bond, causing swelling of the carrier and release of insulin. Insulin can be conjugated with PBA, competitive binding of glucose in the physiological fluid with PBA causes the release of insulin. Many of the studies conducted on such phenylboronic acid based insulin delivery system is summarized in Table 3.

\section{Bulk hydrogels}

3D structure of hydrogel contains a considerable amount of water and it is maintained via chemical or physically crosslinked 3D polymeric scaffold. The incorporation of PBA into the polymeric network provides glucose-responsive hydrogel in presence of increased glucose concentration in the physiological fluid. Increased free glucose concentration causes the formation of boronate ester inducing increased hydrophilicity of polymeric chain ultimately leading to dissociation of polymeric gel and release of insulin.

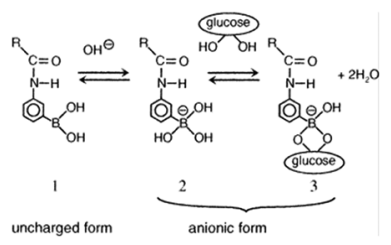

Examples of such bulk hydrogel are hydrogel matrix with major component poly ( $\mathrm{N}$-isopropylacrylamide) (PNIPAAm) derivatized with a definite fraction of a PBA group as the glucose-sensing moiety.



linker [27], polymeric gel composed of poly ( $\mathrm{N}$-isopropylacrylamide) (PNIPAAm), and 3-acrylamidophenylboronic acid (AAPBA) (9:1 in molar ratio: NB10 gel) $[28,29]$. Hydrogels with copolymerization of AAPBA and 2-hydroxyethyl methacrylate [30].

\section{CONCLUSION}

Diabetes is a chronic metabolic health disorder that is affecting a huge population all across the globe. Subcutaneous administration of insulin remains one the conventional and most used therapy in case of insulin deficiency related to diabetes. However, the use of subcutaneous injections for insulin leads to patient non-compliance due to pain, discomfort, and chances of local infections linked to it. An approach towards the use of oral administration of insulin through novel drug delivery systems can lead to patient acceptability as well as it can mimic the action of body physiological insulin. Along with that utilization of different glucose-responsive elements and their incorporation into various novel drug delivery systems help to produce glucose-responsive insulin delivery into the blood circulation giving a closed-loop insulin delivery. Emerging smart insulin delivery systems are based on a glucose-responsive insulin delivery system. Current researches with in vitro and in vivo data prove to improve the diabetes mellitus condition by proper maintenance of glucose concentration in the blood circulation. Glucoresponsive release can reduce the sudden decrease in blood glucose level that might result in some cases after the administration of insulin. Thus, glucose-responsive insulin release can prove to be an effective way of insulin delivery without frequent testing of blood glucose levels. Apart from the advantages of a glucoseresponsive insulin delivery system, there are many problems linked to it that need to be solved. First, degradation of insulin at the gastric fluid due to the presence of peptidase enzymes, secondly the insulin loading capacity on the novel drug delivery systems. Since the release of insulin is controlled by the blood glucose level, the concentration of insulin should be optimum in the release system for a proper release. Further evidence is needed to prove the safety of smart insulin delivery systems in long-term usage. Systematic studies on the metabolic mechanisms of the monomers, polymers, and degradation compounds should also be carried out.

\section{AUTHORS CONTRIBUTION}

All the authors have contributed towards the preparation of review preparation and editing of the manuscript.

\section{CONFLICTS OF INTEREST}

All the authors have none to declare.

\section{AUTHOR FUNDING}

No funding received for the completion and publication of the article. 


\section{REFERENCES}

1. Wang J, Wang Z, Yu J, Kahkoska AR, Buse JB, Gu Z. Glucoseresponsive insulin and delivery systems: Innovation and translation. Adv Mater 2020;32:1902004.

2. Li X, Fu M, Wu J, Zhang C, Deng X, Dhinakar A, et al. pH-sensitive peptide hydrogel for glucose-responsive insulin delivery. Acta Biomater 2017:51:294-303.

3. Jamwal S, Ram B, Ranote S, Dharela R, Chauhan GS. New glucose oxidase-immobilized stimuli-responsive dextran nanoparticles for insulin delivery. Int J Biol Macromol. 2019;123:968-78. https://doi. org/10.1016/j.ijbiomac.2018.11.147 PMid:30448487

4. Yang J, Cao Z. Glucose-responsive insulin release: Analysis of mechanisms, formulations, and evaluation criteria. J Control Release 2017;263:231-9.

5. Kim MY, Kim J. Chitosan microgels embedded with catalase nanozyme-loaded mesocellular silica foam for glucose-responsive drug delivery. ACS Biomater Sci Eng 2017;3:572-8.

6. Zhou X, Wu H, Long R, Wang S, Huang H, Xia Y, et al. Oral delivery of insulin with intelligent glucose-responsive switch for blood glucose regulation. J Nanobiotechnol 2020;18:96.

7. Yu J, Zhang Y, Ye Y, DiSanto R, Sun W, Ranson D, et al. Microneedlearray patches loaded with hypoxia-sensitive vesicles provide fast glucose-responsive insulin delivery. Proc Natl Acad Sci U S A 2015;112:8260-5.

8. Yu J, Qian C, Zhang Y, Cui Z, Zhu Y, Shen Q, et al. Hypoxia and $\mathrm{H}_{2} \mathrm{O}_{2}$ dual-sensitive vesicles for enhanced glucose-responsive insulin delivery. Nano Lett 2017;17:733-9.

9. $\mathrm{Hu}$ X, Yu J, Qian C, Lu Y, Kahkoska AR, Xie Z, et al. $\mathrm{H}_{2} \mathrm{O}_{2}$-responsive vesicles integrated with transcutaneous patches for glucose-mediated insulin delivery. ACS Nano 2017;11:613-20.

10. Tong Z, Zhou J, Zhong J, Tang Q, Lei Z, Luo H, et al. Glucose- and $\mathrm{H}_{2} \mathrm{O}$-responsive polymeric vesicles integrated with microneedle patches for glucose-sensitive transcutaneous delivery of insulin in diabetic rats. ACS Appl Mater Interfaces 2018;10:20014-24.

11. Liu X, Li C, Lv J, Huang F, An Y, Shi L, et al. Glucose and $\mathrm{H}_{2} \mathrm{O}_{2}$ dualresponsive polymeric micelles for the self-regulated release of insulin. ACS Appl Bio Mater 2020;3:1598-606.

12. Miyata T, Jikihara A, Nakamae K, Hoffman AS. Preparation of poly(2glucosyloxyethyl methacrylate)-concanavalin A complex hydrogel and its glucose-sensitivity. Macromol Chem Phys 1996;197:1135-46.

13. Miyata T, Jikihara A, Nakamae K, Hoffman AS. Preparation of reversibly glucose-responsive hydrogels by covalent immobilization of lectin in polymer networks having pendant glucose. J Biomater Sci Polym Ed 2004; 15:1085-98.

14. Available from: https://www.obaidat1996.pdf

15. Yin R, Wang K, Du S, Chen L, Nie J, Zhang W. Design of genipincrosslinked microgels from concanavalin A and glucosyloxyethyl acrylated chitosan for glucose-responsive insulin delivery. Carbohydr Polym 2014;103:369-76.

16. Ye T, Yan S, Hu Y, Ding L, Wu W. Synthesis and volume phase transition of concanavalin A-based glucose-responsive nanogels. Polym Chem 2014;5:186-94.

17. Zhang R, Tang M, Bowyer A, Eisenthal R, Hubble J. Synthesis and characterization of a d-glucose sensitive hydrogel based on CM-dextran and concanavalin A. React Funct Polym 2006;66:757-67.

18. Tanna S, Taylor MJ, Sahota TS, Sawicka K. Glucose-responsive UV polymerised dextran-concanavalin A acrylic derivatised mixtures for closed-loop insulin delivery. Biomaterials 2006;27:1586-97.

19. Taylor MJ, Tanna S, Sahota TS, Voermans B. Rheological characterisation of dextran-concanavalin A mixtures as a basis for a selfregulated drug delivery device. Eur J Pharm Biopharm 2006;62:94-100.

20. Krug AW, Visser SA, Tsai K, Kandala B, Fancourt C, Thornton B, et al. Clinical evaluation of MK-2640: An insulin analog with glucoseresponsive properties. Clin Pharmacol Ther 2019;105:417-25.

21. Kaarsholm NC, Lin S, Yan L, Kelly T, van Heek M, Mu J, et al. Engineering glucose responsiveness into insulin. Diabetes 2018;67:299-308.

22. Brownlee M, Cerami A. Glycosylated insulin complexed to concanavalin A. Biochemical basis for a closed-loop insulin delivery system. Diabetes 1983;32:494-504.

23. Wang J, Yu J, Zhang Y, Kahkoska AR, Wang Z, Fang J, et al. Glucose transporter inhibitor-conjugated insulin mitigates hypoglycemia. Proc Natl Acad Sci U S A 2019;166:10744-8.

24. Wang C, Ye Y, Sun W, Yu J, Wang J, Lawrence DS, et al. Red blood cells for glucose-responsive insulin delivery. Adv Mater 2017;29:201606617.
25. Wang J, Wang Z, Yu J, Zhang Y, Zeng Y, Gu Z. A forskolin-conjugated insulin analog targeting endogenous glucose-transporter for glucoseresponsive insulin delivery. Biomater Sci 2019;7:4508-13.

26. Kuivila HG, Keough AH, Soboczenski EJ. Areneboronates from diols and polyols. J Org Chem 1954;19:780-3.

27. Kataoka K, Miyazaki H, Bunya M, Okano T, Sakurai Y. On-off regulation of insulin-release by totally synthetic polymer gels responding to external glucose concentration. Am Chem Soc Polym Prepr Div Polym Chem 1999;40:301-2.

28. Matsumoto A, Kurata T, Shiino D, Kataoka K. Swelling and shrinking kinetics of totally synthetic, glucose-responsive polymer gel bearing phenylborate derivative as a glucose-sensing moiety. Macromolecules 2004;37:1502-10.

29. Matsumoto A, Yoshida R, Kataoka K. Glucose-responsive polymer gel bearing phenylborate derivative as a glucose-sensing moiety operating at the physiological pH. Biomacromolecules 2004;5:1038-45.

30. Lee YJ, Pruzinsky SA, Braun PV. Glucose-sensitive inverse opal hydrogels: Analysis of optical diffraction response. Langmuir 2004;20:3096-106.

31. Zhang Y, Wang J, Yu J, Wen D, Kahkoska AR, Lu Y, et al. Bioresponsive microneedles with a sheath structure for $\mathrm{H}_{2} \mathrm{O}_{2}$ and $\mathrm{pH}$ cascade-triggered insulin delivery. Small 2018;14:1704181.

32. Yu J, Zhang Y, Wang J, Wen D, Kahkoska AR, Buse JB, et al. Glucoseresponsive oral insulin delivery for postprandial glycemic regulation. Nano Res 2019;12:1539-45.

33. Li C, Liu X, Liu Y, Huang F, Wu G, Liu Y, et al. Glucose and H 2 O 2 dual-sensitive nanogels for enhanced glucose-responsive insulin delivery. Nanoscale 2019;11:9163-75.

34. Zhang C, Hong S, Liu MD, Yu WY, Zhang MK, Zhang L, et al. pHsensitive MOF integrated with glucose oxidase for glucose-responsive insulin delivery. J Control Release 2020;320:159-67.

35. Yin R, He J, Bai M, Huang C, Wang K, Zhang H, et al. Engineering synthetic artificial pancreas using chitosan hydrogels integrated with glucose-responsive microspheres for insulin delivery. Mater Sci Eng C. 2019;96:374-82. https://doi.org/10.1016/j.msec.2018.11.032 PMid:30606545

36. Di J, Yu J, Ye Y, Ranson D, Jindal A, Gu Z. Engineering synthetic insulin-secreting cells using hyaluronic acid microgels integrated with glucose-responsive nanoparticles. Cell Mol Bioeng 2015;8:445-54.

37. Zuo M, Qian W, Xu Z, Shao W, Hu XY, Zhang D, et al. Multiresponsive supramolecular theranostic nanoplatform based on pillar [5] arene and diphenylboronic acid derivatives for integrated glucose sensing and insulin delivery. Small 2018;14:1801942.

38. Liu X, Li C, Lv J, Huang F, An Y, Shi L, et al. Glucose and H2O2 dualresponsive polymeric micelles for the self-regulated release of insulin. ACS Appl Biomater. 2020;3(3):1598-606. https://doi.org/10.1021/ acsabm.9b01185 PMid:35021650

39. Mohammadpour F, Hadizadeh F, Tafaghodi M, Sadri K, Mohammadpour AH, Kalani MR, et al. Preparation, in vitro and in vivo evaluation of PLGA/Chitosan based nano-complex as a novel insulin delivery formulation. Int J Pharm 2019;572:118710.

40. Chu MK, Chen J, Gordijo CR, Chiang S, Ivovic A, Koulajian K, et al. In vitro and in vivo testing of glucose-responsive insulin-delivery microdevices in diabetic rats. Lab Chip 2012;12:2533-9.

41. Chen S, Matsumoto H, Moro-Oka Y, Tanaka M, Miyahara Y, Suganami $\mathrm{T}$, et al. Smart microneedle fabricated with silk fibroin combined semi-interpenetrating network hydrogel for glucose-responsive insulin delivery. ACS Biomater Sci Eng 2019;5:5781-9. https://doi. org/10.1021/acsbiomaterials.9b00532 PMid:33405670

42. Fu Y, Liu W, Wang LY, Zhu BY, Qu MK, Yang LQ, et al. Erythrocytemembrane-camouflaged nanoplatform for intravenous glucoseresponsive insulin delivery. Adv Function Mater 2018;28:1802250.

43. Gu Z, Dang TT, Ma M, Tang BC, Cheng H, Jiang S, et al. Glucoseresponsive microgels integrated with enzyme nanocapsules for closedloop insulin delivery. ACS Nano 2013;7:6758-66.

44. Gordijo CR, Shuhendler AJ, Wu XY. Glucose-responsive bioinorganic nanohybrid membrane for self-regulated insulin release. Adv Function Mater 2010;20:1404-12.

45. Chu MK, Gordijo CR, Li J, Abbasi AZ, Giacca A, Plettenburg O, et al. In vivo performance and biocompatibility of a subcutaneous implant for real-time glucose-responsive insulin delivery. Diabetes Technol Ther 2015;17:255-67.

46. Jo SM, Lee HY, Kim JC. Glucose-sensitivity of liposomes incorporating conjugates of glucose oxidase and poly $\mathrm{N}$-isopropylacrylamideco-methacrylic acid-co-octadecylacrylate. Int J Biol Macromol 
2009;45:421-6.

47. Li X, Shang H, Wu W, Li S, Lin Z, Duan J, et al. Glucose-responsive micelles for controlled insulin release based on transformation from amphiphilic to double hydrophilic. J Nanosci Nanotechnol 2016;16:5457-63.

48. Cheng K, Zhang Y, Li Y, Gao Z, Chen F, Sun K, et al. A novel pHresponsive hollow mesoporous silica nanoparticle (HMSN) system encapsulating doxorubicin (DOX) and glucose oxidase (GOX) for potential cancer treatment. J Mater Chem B 2019;7:3291-302.

49. Jamwal S, Ram B, Ranote S, Dharela R, Chauhan GS. New glucose oxidase-immobilized stimuli-responsive dextran nanoparticles for insulin delivery. Int J Biol Macromol 2019;123:968-78.

50. Oroval M, Díez P, Aznar E, Coll C, Marcos MD, Sancenón F, et al. Self-regulated glucose-sensitive neoglycoenzyme-capped mesoporous silica nanoparticles for insulin delivery. Chem Eur J 2017;23:1353-60.

51. Agazzi M, Herrera S, Cortez ML, Marmisollé W, Tagliazucchi M, Azzaroni O. Insulin-delivery from glucose-responsive self-assembled polyamine nanoparticles: Smart "Sense-and-Treat" nanocarriers made easy. Chem Eur J 2019;26:2456-63.

52. Baena-Díez JM, Peñafiel J, Subirana I, Ramos R, Elosua R, MarínIbañez A, et al. Risk of cause-specific death in individuals with diabetes: A competing risks analysis. Diabetes Care 2016;39:1987-95.

53. Shaw JE, Sicree RA, Zimmet PZ. Global estimates of the prevalence of diabetes for 2010 and 2030. Diabetes Res Clin Pract 2010;87:4-14.

54. Guariguata L, Linnenkamp U, Beagley J, Whiting DR, Cho NH. Global estimates of the prevalence of hyperglycaemia in pregnancy. Diabetes
Res Clin Pract 2014;103:176-85.

55. Blas E, Kurup AS, editors. Equity, Social Determinants and Public Health Programmes. Geneva: World Health Organization; 2010.

56. International Diabetes Federation. IDF Diabetes Atlas. $7^{\text {th }}$ ed. Brussels, Belgium: International Diabetes Federation; 2015. Available from: http://www.diabetesatlas.org

57. Brown AF, Ettner SL, Piette J, Weinberger M, Gregg E, Shapiro MF, et al. Socioeconomic position and health among persons with diabetes mellitus: A conceptual framework and review of the literature. Epidemiol Rev 2004;26:63-77.

58. Shen D, Yu H, Wang L, Khan A, Haq F, Chen X, et al. Recent progress in design and preparation of glucose-responsive insulin delivery systems. J Control Release 2020;321:236-58.

59. Kim SK, Jeon C, Lee GH, Koo J, Cho SH, Han S, et al. Hyaluronate gold nanoparticle/glucose oxidase complex for highly sensitive wireless noninvasive glucose sensors. ACS Appl Mater Interf. 2019;11(40):37347-56. https://doi.org/10.1021/acsami.9b13874 PMid:31502433

60. Huang Q, Wang L, Yu H, Ur-Rahman K. Advances in phenylboronic acid-based closed-lovop smart drug delivery system for diabetic therapy. J Controll Release. 2019;305:50-64. https://doi. org/10.1016/j.jconrel.2019.05.029 PMid:31112719

61. Chang R, Li M, Ge S, Yang J, Sun Q, Xiong L. Glucose-responsive biopolymer nanoparticles prepared by co-assembly of concanavalin A and amylopectin for insulin delivery. Ind Crops Prod 2018;112:98-104. 